\title{
SERIAL N-TERMINAL PRO-BRAIN NATRIURETIC PEPTIDE MEASUREMENT AS A PREDICTOR OF CLINICALLY SIGNIFICANT DUCTUS ARTERIOSUS IN PRETERM INFANTS BEYOND THE FIRST WEEK OF LIFE
}

\author{
J.B. Letshwiti ${ }^{1}$, J. Sirc $^{1,2}$, R. O'Kelly ${ }^{3}$, J. Miletin ${ }^{1,2}$ \\ ${ }^{I}$ Coombe Women and Infants University Hospital, Dublin, Ireland, ${ }^{2}$ Institute for the Care of Mother and \\ Child, Prague, Czech Republic, ${ }^{3}$ Biochemistry Department, Coombe Women and Infants University Hospital, \\ Dublin, Ireland
}

Background and aims: Previous studies have mainly looked at the significance of biochemical markers in predicting significant patent ductus arteriosus (PDA) within the first week of life. The aim of the study was to assess the value of plasma N-terminal pro-brain natriuretic peptide (NT-proBNP) concentration as a predictor of PDA in very preterm infants beyond the first week of life.

Methods: A prospective observational study was undertaken at the Coombe Women \& Infants University Hospital, Dublin, Ireland. Newborns with birth weight $<1500 \mathrm{~g}$ were eligible for enrolment. Enrolled infants were screened by echocardiography (ECHO) on day 7 of life for the presence of a PDA. This was paired with a blood sample for NT-proBNP level. ECHO and NT-proBNP levels were repeated at weekly intervals in those with a PDA until the duct closed or the baby discharged.

Results: Seventy neonates were enrolled following parental consent. The mean birth weight was $1119 \mathrm{~g}$ $( \pm 257)$ and the mean gestational age was 28.6 weeks ( \pm 2.6$)$. Median NT-proBNP level on day 7 was 11469 $\mathrm{ng} / \mathrm{l}$ in infants with PDA vs. $898 \mathrm{ng} / \mathrm{l}$ in infants without PDA $(\mathrm{p}<0.0001)$. There was a statistically significant correlation between PDA diameter and NT-proBNP level on day 7, day 14 and day $21(\mathrm{p}=0.0007$, $\mathrm{p}<0.0001, \mathrm{p}=0.03$ ). There was no correlation between Left Atrium to Aorta ratio and NT-proBNP in the first 21 days of life.

Conclusion: NT-proBNP concentration was significantly increased in infants with PDA. NT-proBNP correlates best with PDA diameter in the first three weeks of life. 